\title{
A Neuroleptic Malignant Syndrome Without Rigidity
}

\author{
İlker Özdemir ${ }^{\bowtie}$, Erkan Kuru², Yasir Safak $^{3}$, and Rıza Gökçer Tulacı ${ }^{4}$ \\ ${ }^{1}$ Doç. Dr. Mustafa Kalemli Tavşanılı State Hospital, Psychiatry Clinic, Kütahya, Turkey \\ ${ }^{2}$ Boylam Private Psychiatric Hospital, Ankara, Turkey \\ ${ }^{3}$ Dışkapı Yıldırım Beyazıt Teaching and Research Hospital, Psychiatry Clinic, Ankara, Turkey \\ ${ }^{4}$ Uşak State Hospital, Psychiatry Clinic, Uşak, Turkey
}

\begin{abstract}
Neuroleptic malignant syndrome (NMS) is an uncommon but potentially lethal idiosyncratic reaction which may emerge in the aftermath of the treatments with neuroleptics demonstrating itself with the symptoms of altered consciousness, high fever, impaired autonomic functions, and muscle rigidity. Although various risk factors have been identified for NMS, its etiology is not completely known. The mortality and morbidity related with NMS could be reduced by early diagnosis, interruption of the neuroleptics used within a short period and aggressive treatment. Our case is different from general NMS cases due to lack of rigidity. A NMS case which developed within a short time in the aftermath of multiple antipsychotic use and wherein no rigidity was observed shall be discussed in this case report.

Psychiatry Investig 2018;15(2):226-229
\end{abstract}

Key Words Neuroleptic malignant syndrome, Muscular rigidity, Antipsychotic agents.

\section{INTRODUCTION}

Neuroleptic malignant syndrome (NMS) is an uncommon clinical picture related with antipsychotic use; however, it is one that cannot be predicted and may be lethal. ${ }^{1}$ Its typical symptoms and signs may be seen as fever, muscular rigidity, altered consciousness (confusion, stupor, coma), disorders pertaining to the autonomous nervous system (hypertension, tachycardia, tachypnea, sweating, urinary incontinence), and deterioration in various blood values [decrease in serum electrolytes, increase in creatinine phosphokinase (CPK), leukocytosis]. ${ }^{2}$ Patients usually encounter a dopamine antagonist within 72 hours of symptoms onset. Common rigidity which usually does not respond to antiparkinson drugs, is an important feature of this disorder. Electroencephalography (EEG) demonstrates a general slowdown, whereas cerebrospinal fluid (CSF) examinations and neuroimaging studies are usually ordinary. $^{3}$

Received: January 3, 2017 Revised: May 28, 2017

Accepted: June 5, 2017 Available online: December 14, 2017

$\triangle$ Correspondence: İlker Özdemir, MD

Doç. Dr. Mustafa Kalemli Tavşanlı State Hospital, Psychiatry Clinic, Kavaklı Street, No:1, Tavşanl, Kütahya 43300, Turkey

Tel: +905055873405 , Fax: +902746151426

E-mail: ilkerozdemir249@yahoo.com

(c) This is an Open Access article distributed under the terms of the Creative Commons Attribution Non-Commercial License (http://creativecommons.org/licenses/by$\mathrm{nc} / 4.0$ ) which permits unrestricted non-commercial use, distribution, and reproduction in any medium, provided the original work is properly cited.
The incidence rate of NMS ranges between $0.01-0.02 \%{ }^{4}$ Symptoms begin hours-days after starting the drug. It develops within 30 days at the latest in nearly all cases. The average recovery period is 7-10 days in the aftermath of medication discontinuation. ${ }^{5}$ It was reported that the mortality rate was about $10-20 \%$ when NMS was not identified. ${ }^{6,7}$ Parenteral administration, rapid dose adjustments and higher total drug doses have increased the possibility of this syndrome's occurrence; however, NMS usually emerges in the therapeutic dose range of antipsychotics. ${ }^{8}$ NMS is more frequently seen with typical antipsychotics as compared with atypical antipsychotics. ${ }^{1,9}$ Treatment usually consists of discontinuation of the causative agent and supportive treatment under intensive care conditions, supplying intensive hydration therapy and treatment with dantrolene or bromocriptine. ${ }^{10}$

The patient discussed herein was tracked in the psychiatric service for diagnostic purposes; this was a short-term case of NMS that developed in the aftermath of multiple antipsychotic use in a patient who had no prior history of antipsychotic treatment in which no rigidity was observed.

\section{CASE}

The patient was a 49 -year-old male civil servant who was married and a secondary school graduate. The patient presented to our outpatient clinic with symptoms of insomnia, 
loss of appetite, behavior change, suspicion, thought about being harmed by others, and forgetfulness which had continued for about two months. The patient was admitted to our service for diagnosis and treatment.

On the day of admission to hospital, in his first psychiatric examination his consciousness was clear, the place-time-person orientation was full, but his self-care was poor. He had euthymic mood and his affection was limited. A memory pathology was not considered. His attention was observed as normal. No perceptual pathology was observed. His intelligence seemed normal. He had a circumstantial, sometimes tangential process of thinking. He had delusions of persecution in his thought content. No suicidal thoughts were observed. He was assessed as to have no insight, and a distorted ability to judge and evaluate reality.

No pathology was detected in routine examinations that were requested on the day of admission. The patient was immediately started on quetiapine $200 \mathrm{mg}$ /day because of his active psychotic symptoms. The patient had confusion during his first night of hospitalization, he was agitated and said that he wanted to go home and attempted to jump out of the window. Upon which, the patient was restrained and a zuclopenthixol $50 \mathrm{mg} / \mathrm{mL}$ intramuscular (IM) injection was administered to provide sedation for that night. The patient could not be sedated, and thus was given chlorpromazine $75 \mathrm{mg} \mathrm{IM}$, haloperidol $15 \mathrm{mg} \mathrm{IM}$, and clonazepam $2 \mathrm{mg}$ tablets, respectively, at one-hour intervals for 3 hours.
The treatment was reevaluated on the second day of admission, and was arranged as olanzapine $20 \mathrm{mg} / \mathrm{day}$, and a 10 $\mathrm{mg}$ haloperidol IM injection was applied due to his agitation.

The patient's temperature was $39^{\circ} \mathrm{C}$ in the morning of the 3 rd day. Recurrent oral fever measurements were also detected above $39^{\circ} \mathrm{C}$. His blood pressure varied; the systolic blood pressure ranged from 80 to $160 \mathrm{~mm} \mathrm{Hg}$. Although he was inclined to sleep, he responded to verbal stimulants. His extrapyramidal symptoms were evaluated using the Extrapyramidal Symptom Rating Scale and no rigidity was detected. According to this scale, his rigidity subscale score was 0 . Increases in his biochemical parameters were detected in laboratory investigations. In the follow-up, the patient's aspartate aminotransferase (AST) and creatinine phosphokinase (CPK) were high at $993 \mathrm{U} / \mathrm{L}$ and $38247 \mathrm{U} / \mathrm{L}$, respectively, and his white blood cells (WBC) were $12.6 \mathrm{~K} / \mathrm{uL}$, normal prothrombin time was INR: $1.22 \mathrm{IU}$, and his activated partial thromboplastin time (aPTT) was $36.5 \mathrm{sec}$. Infectious Diseases and Neurology departments were consulted. Cranial computerized tomography (CT), magnetic resonance imaging (MRI), and EEG were within normal limits. Encephalitis, meningitis, and possible neurologic and infectious diseases were excluded.

NMS was diagnosed upon observing altered consciousness (confusion, somnolence), elevation of fever, sweating, blood pressure variability, CPK and AST elevation, and leukocytosis in his examination.

Follow-up of the patient began in the intensive care unit

Table 1. The patient's medication, dose, and symptoms as time progressed

\begin{tabular}{|c|c|c|}
\hline Time period & Medication and dosage & Symptoms \\
\hline $\begin{array}{l}\text { First day } \\
\text { of admission }\end{array}$ & $\begin{array}{l}\text { 18:00-Quetiapine } 200 \mathrm{mg} \text { tab } \\
\text { 23:00-Chlorpromazine } 50 \mathrm{mg} \text { IM } \\
\text { 00:00-Haloperidol } 10 \mathrm{mg} \text { IM+Chlorpromazine } 25 \mathrm{mg} \mathrm{IM} \\
\text { 01:00-Clonazepam } 2 \mathrm{mg} \text { tab+Haloperidol } 5 \mathrm{mg} \mathrm{IM}\end{array}$ & $\begin{array}{l}\text { Consciousness was clear } \\
\text { Full place-time-person orientation } \\
\text { Circumstantial, sometimes tangential thinking } \\
\text { Delusions of persecution } \\
\text { Normal biochemical parameters }\end{array}$ \\
\hline $\begin{array}{l}\text { Second day } \\
\text { of admission }\end{array}$ & $\begin{array}{l}\text { 13:00-Olanzapine } 20 \mathrm{mg} \text { tab } \\
\text { 20:00-Haloperidol } 10 \mathrm{mg} \text { IM }\end{array}$ & $\begin{array}{l}\text { Confusion } \\
\text { Agitation } \\
\text { Circumstantial, sometimes tangential thinking } \\
\text { Delusions of persecution }\end{array}$ \\
\hline $\begin{array}{l}\text { Third day } \\
\text { of admission }\end{array}$ & $\begin{array}{l}\text { Antipsychotic medication stopped } \\
\text { 09:00-Paracetamol } 10 \mathrm{mg} / \mathrm{mL} 100 \mathrm{~mL} \mathrm{IV}+1000 \mathrm{cc} \\
\text { isotonic solution IV } \\
\text { 13:00-Paracetamol } 10 \mathrm{mg} / \mathrm{mL} 100 \mathrm{~mL} \mathrm{IV} \\
\text { 18:00-Paracetamol } 10 \mathrm{mg} / \mathrm{mL} 100 \mathrm{~mL} \mathrm{IV}+500 \mathrm{cc} \\
\text { dextrose } 5 \% \mathrm{IV} \\
\text { 20:00-Transferred to the intensive care unit }\end{array}$ & $\begin{array}{l}\text { Temperature } 39^{\circ} \mathrm{C} \text {. Recurrent measurements were all } \\
\text { above } 39^{\circ} \mathrm{C} \\
\text { Systolic blood pressure ranged from } 80 \text { to } 160 \mathrm{~mm} \mathrm{Hg} \\
\text { Inclination to sleep, he responded to verbal stimulants } \\
\text { AST: } 993 \mathrm{U} / \mathrm{L} \text { and CPK: } 38247 \mathrm{U} / \mathrm{L} \text { WBC: } 12.6 \mathrm{~K} / \mathrm{uL} \text {, } \\
\text { INR: } 1.22 \mathrm{IU} \text { and APTT: } 36.5 \mathrm{sec} \\
\text { Cranial CT, MRI, and EEG within normal limits }\end{array}$ \\
\hline $4-12$ th days & Intensive hydration therapy daily & $\begin{array}{l}\text { Fever, blood pressure, and biochemical parameters } \\
\text { (AST, CPK and WBC levels) were at normal levels } \\
\text { Volatility of consciousness remained }\end{array}$ \\
\hline
\end{tabular}

IM: intramuscular, IV: intravenous, AST: aspartate aminotransferase, CPK: creatinine phosphokinase, WBC: white blood cells, INR: international normalized ratio, APTT: activated partial thromboplastin time, CT: computerized tomography, MRI: magnetic resonance imaging, EEG: electroencephalography 
(ICU). The patient's fever subsided after 8 days of intensive hydration in the ICU and his blood values returned to normal limits. His medication, doses, and symptoms as time progressed are presented in Table 1.

\section{DISCUSSION}

According to the Diagnostic and Statistical Manual of Men- tal Disorders, Fourth Edition Text Revision (DSM-IV-TR), NMS is diagnosed upon the existence of two or more of the following findings: fever and muscular rigidity (major findings), sweating, tachycardia, altered or generally elevated arterial tension, elevated white blood cell count, altered consciousness, tremor, urinary-fecal incontinence, and elevated CPK (minor findings). ${ }^{11}$ Regarding NMS, which is reported under the heading of "drug-induced motion disorders and oth-

Table 2. Diagnostic Criteria of NMS

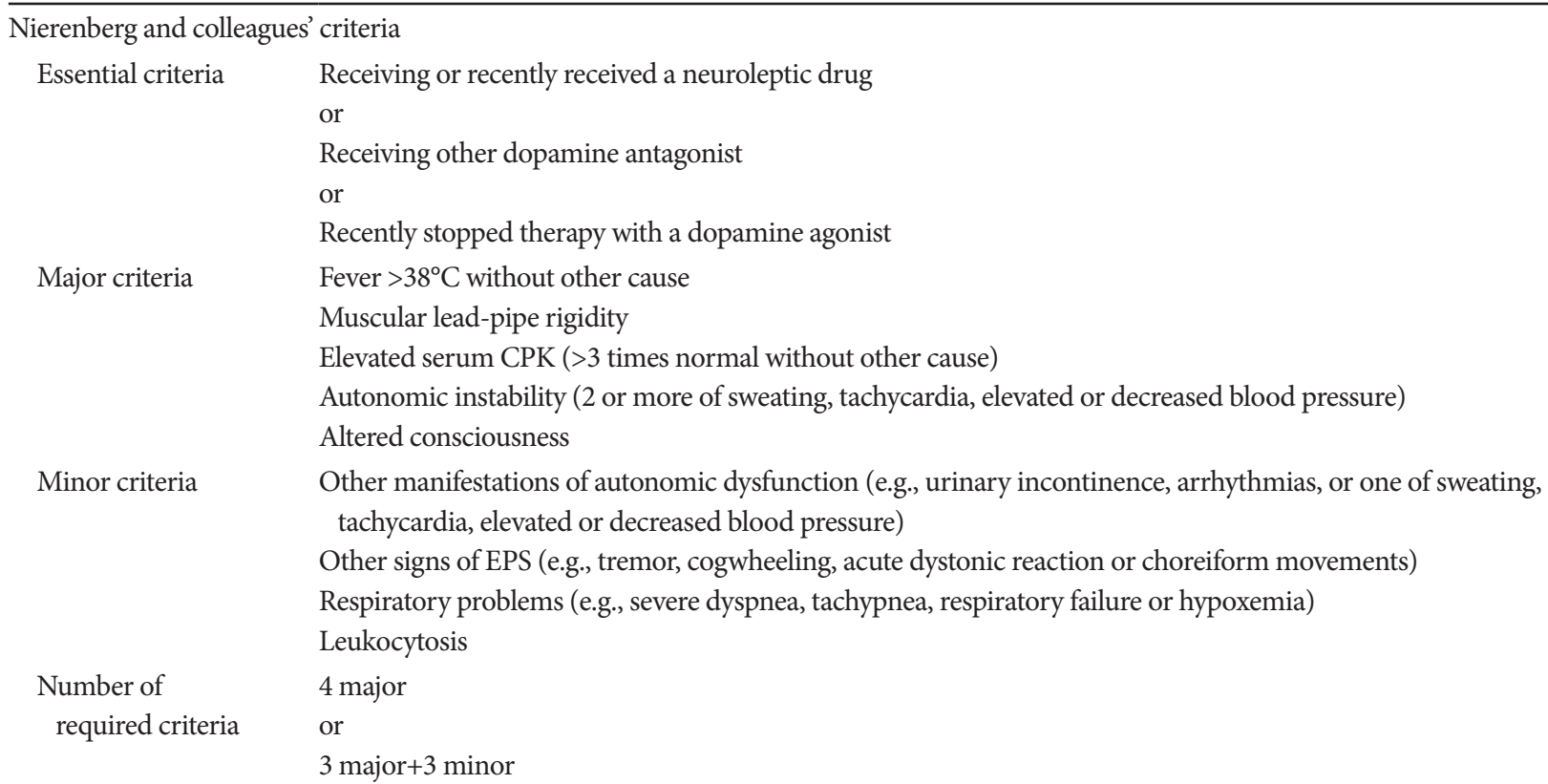

DSM-IV criteria

Criteria A The development of severe muscle rigidity

Elevated temperature associated with the use of antipsychotic medication

Criteria B Diaphoresis

Elevated or labile blood pressure

Tachycardia

Incontinence

Dysphagia

Mutism

Tremor

Changes in the level of consciousness ranging from confusion to coma

Leukocytosis

Laboratory evidence of muscle injury (e.g., elevated CPK)

Criteria C The symptoms in Criteria A and B are not due to another substance, neurologic or other medical conditions

Criteria D The symptoms in Criteria A and B are not better accounted for by a mental disorder

Number of required Both two items of criteria A and two or more items of criteria $B$

criteria

DSM-5

No specific criteria NMS is classified as hyperthermia, rigidity, mental status alteration, CPK elevation, sympathetic nervous system lability and hypermetabolism after exposure to dopamine antagonist or dopamine agonist withdrawal, with a negative examination for infectious, toxic, metabolic and neurologic causes

NMS: neuroleptic malignant syndrome, CPK: creatinine phosphokinase, EPS: extrapyramidal side effects, DSM-IV: Diagnostic and Statistical Manual of Mental Disorders, Fourth Edition, DSM-5: Diagnostic and Statistical Manual of Mental Disorders, Fifth Edition 
er side effects of medicines" in the fifth edition of the Diagnostic and Statistical Manual of Mental Disorders (DSM-5), although it is stated that the symptoms mentioned in DSM-IVTR have been observed, a diagnosis criterion classification has not been made such as that in DSM-IV-TR. ${ }^{8}$

Patient diagnosed as having NMS according to the DSM-5 and Nierenberg diagnostic criteria, cannot be diagnosed as having NMS according to DSM-IV. ${ }^{8,12}$ The arrangement made in DSM-5 for NMS has also been useful from the aspect of helping patients to be diagnosed and treated more easily. DSM-IVTR, DSM-5, and the Nierenberg diagnosistic criteria are presented in Table 2.

The absence of rigidity in spite of high fever and elevated CPK values is a different situation from typical NMS. Although rigidity is a major criterion, patients with NMS who had no rigidity have been described in the literature. ${ }^{13}$ It is very difficult to diagnose NMS in patients with no elevation of temperature or muscular rigidity. ${ }^{14}$ From this point of view, it is thought that such a case is important in terms of its contribution to the literature.

It was reported that in approximately $10-40 \%$ of NMS cases caused by atypical antipsychotics, fever and rigidity were lighter or only one could be found. ${ }^{15}$ In the absence of such major symptoms, diagnosis may be delayed due to the inadvertent assessment of deterioration of primary psychotic disorder, extrapyramidal effects of drugs, or delirium associated with neurologic, infectious or other causes. ${ }^{16}$ Even if there is no rigidity in line with such cases, it should be emphasized that NMS must be suspected in the presence of other symptoms.

The risk factors for NMS are specified as the initiation of drugs that reduce levels of dopamine, dose increases in such drugs, the use of medications in depot form, multiple drug use, dehydration of the patient, past NMS experience, brain injury or mental retardation in the patient. ${ }^{17}$ It was reported that there was limited information on persistent sequelae levels in the aftermath of NMS, the rate of which is between $3.3-10 \%{ }^{18}$ Death is often caused by respiratory problems, cardiac arrest or kidney failure, which developing along with muscle destruction. The most important approach to reduce mortality is to promptly diagnose NMS and monitor patients under intensive care settings. ${ }^{19}$

Regarding treatment, first, the drugs being used should be discontinued, the patient's fever should be lowered, and the provision of hydration is recommended. In addition, initiation of dantrolene, bromocriptine, and benzodiazepine accelerates clinical improvement. ${ }^{1,20}$

Our patient was followed up under intensive care settings and through rigorous hydration therapy without the need for additional medical treatment. The AST, CPK, WBC levels, and fever, which were initially high, returned to normal. However, the volatility of consciousness has continued, although this is rare. NMS is a condition that needs immediate identification and urgent treatment. The mortality rate is very high when not diagnosed or treatment is delayed. Therefore, it should be remembered that NMS may develop in all patients using antipsychotics, it should be diagnosed early, and treatment should be started rapidly.

\section{REFERENCES}

1. Nielsen J, Bruhn AM. Atypical neuroleptic malignant syndrome caused by olanzapine. Acta Psychiatr Scand 2005;112:238-240.

2. Semiz ÜB. Neuroleptic Malignant Syndrome: In: Ceylan ME, Çetin M, Editors). Schizophrenia. 4th Edition. Istanbul: İncekara Matbaacilık, 2009, p.167-176.

3. Tural Ü, Önder E. Clinical and pharmacologic risk factors for neuroleptic malignant syndrome and their association with death. Psychiatry Clin Neurosci 2010;64:79-87.

4. Sarkar P, Natarajan C, Gode N. Prevalence of neuroleptic malignant syndrome in 672 consecutive male in patients. Indian J Psychiatry 2009;51:202-205.

5. Chandran GJ, Mikler JR, Keegan DL. Neuroleptic malignant syndrome: case report and discussion. CMAJ 2003;169:439-442.

6. Khaldi S, Kornreich C, Choubani Z, Gourevitch R. Neuroleptic malignant syndrome and atypical antipsychotics: a brief review. Encephale 2008;34:618-624.

7. Öztürk MO, Uluşahin A. Mental Health and Disorders 13th Edition. Ankara: Nobel Tip Kitabevleri; 2015.

8. American Psychiatric Association. Diagnostic and Statistical Manual of Mental Disorders (5th Ed.). Arlingtone, VA: American Psychiatric Publishing; 2013.

9. Kamışlı Ö, Özcan Ö, Kaplan Y, Özcan C. Aripiprazole and neuroleptic malignant syndrome in an adolescent patient: a case report. Arch Neuropsychiatry 2010;47:260-262.

10. Reulbach U, Dütsch C, Biermann T, Sperling W, Thuerauf N, Kornhuber J, et al. Managing an effective treatment for neuroleptic malignant syndrome. Crit Care 2007;11:R4.

11. American Psychiatric Association. Diagnostic and Statistical Manual of Mental Disorders. Fourth Ed., Text Revision. Washington DC: American Psychiatric Association; 2000.

12. Nierenberg D, Disch M, Manheimer E, Patterson J, Ross J, Silvestri G, et al. Facilitating prompt diagnosis and treatment of the neuroleptic malignant syndrome. Clin Pharmacol Ther 1991;50:580-586.

13. Benazzi F. Neuroleptic malignant syndrome without rigidity. Ital J Neurol Sci 1991;12:121.

14. Farver DK. Neuroleptic malignant syndrome induced by a typical antipsychotic. Expert Opin Drug Saf 2003;2:21-35.

15. Ananth J, Parameswaran S, Gunatilake S, Burgoyne K, Sidhom T. Neuroleptic malignant syndrome and atypical antipsychotic drugs. J Clin Psychiatry 2004;65:464-470.

16. Seitz DP. Diagnostic uncertainty in a case of neuroleptic malignant syndrome. Can J Emerg Med 2005;7:266-272.

17. Altındağ A, Yanık M, Nebioğlu M. Neuroleptic malignant syndrome in two brothers with mental retardation. Bull Clin Psychopharm 2004; 14:150-153.

18. Harmanci H, Taycan SE, Çelikel FÇ, Ünaldi HK, Kurt G. Fatal Neuroleptic Malignant Syndrome with Single Dose Olanzapine: A Case Report. Düşünen Adam 2013;26:106.

19. Rajamani B, Kumar Y, Rahman SM. Neuroleptic malignant syndrome. J Family Med Prim Care 2016;5:178-180.

20. Choi HD, Kim KK, Koo BH. A case of catatonia and neuroleptic malignant syndrome probably associated with antipsychotic in Korea. Psychiatry Investig 2011;8:174-177. 